\title{
Ring-fused diphenylchlorins as potent photosensitizers for PDT applications: in vitro tumor cell biology and in vivo chick embryo CAM studies
}

Bruno F. O. Nascimento,${ }^{\dagger}$ Mafalda Laranjo,,$+\perp$ Nelson A. M. Pereira, ${ }^{\dagger}$ João Dias Ferreira,, Marta Piñeiro, ${ }^{\dagger}$ Maria Filomena Botelho, ${ }^{\ddagger} \perp$ Teresa M. V. D. Pinho e Melo*,†

${ }^{\dagger} \mathrm{CQC}$ and Department of Chemistry, University of Coimbra, 3004-535 Coimbra, Portugal Biophysics Institute and Institute for Clinical and Biomedical Research (iCBR), area of Environment Genetics and Oncobiology (CIMAGO), Faculty of Medicine, University of Coimbra, 3004-548 Coimbra, Portugal

${ }^{\perp}$ CNC.IBILI Consortium, University of Coimbra, 3004-548 Coimbra, Portugal

*tmelo@ci.uc.pt

\section{Supporting Information}

\section{Table of contents}

Data regarding the in vivo chick embryo CAM assay treatment groups, conditions, and analyses. 


\section{In vivo chick embryo CAM assay treatment groups, conditions, and analyses}

Table S1. In vivo chick embryo CAM assay treatment groups and conditions. The administration vehicle injected in groups I and III was 1\% DMSO in PBS. The time of illumination needed to reach $2.5 \mathrm{~J} / \mathrm{cm}^{2}$ in groups III and IV was 1 minute at $83 \mathrm{~mW}$. NA: not applicable.

\begin{tabular}{cccccc}
\hline Group & Eggs & Description & $\begin{array}{c}\text { Injection (100 } \\
\boldsymbol{\mu L})\end{array}$ & Concentration (nM) & Light Conditions \\
\hline I & 24 & Control & admin. vehicle & NA & NA \\
II & 20 & Chlorin 3 & Chlorin 3 & 608 & NA \\
III & 21 & Irradiation & admin. vehicle & NA & $2.5 \mathrm{~J} / \mathrm{cm}^{2}$ at $635 \mathrm{~nm}$ \\
IV & 20 & PDT & Chlorin 3 & 608 & $2.5 \mathrm{~J} / \mathrm{cm}^{2}$ at $635 \mathrm{~nm}$ \\
\hline
\end{tabular}

Table S2. In vivo chick embryo CAM assay toxicity analysis, including total, alive and dead chick embryos for each group of eggs after treatment.

\begin{tabular}{cccccc}
\hline \multirow{2}{*}{ Group } & \multicolumn{5}{c}{ Embryos } \\
\cline { 2 - 6 } & Total & Alive & Dead & Alive (\%) & Dead (\%) \\
\hline I & 24 & 17 & 7 & 71 & 29 \\
II & 20 & 17 & 3 & 85 & 15 \\
III & 21 & 11 & 10 & 52 & 48 \\
IV & 20 & 9 & 11 & 45 & 55 \\
\hline
\end{tabular}

Table S3. In vivo chick embryo CAM assay tumor growth analysis, including mean value, SD, SEM, regression and p-value of tumor weight (mg) for each group of eggs after treatment. NA: not applicable.

\begin{tabular}{ccccccccc}
\hline & & \multicolumn{3}{c}{ Tumor Growth Analysis } & \multicolumn{3}{c}{ P-value vs. } \\
\cline { 3 - 8 } Group & Eggs & $\begin{array}{c}\text { Weight } \\
(\mathbf{m g})\end{array}$ & SD & SEM & $\begin{array}{c}\text { Regression } \\
(\%)\end{array}$ & Group I & Group II & Group III \\
\hline I & 17 & 65.51 & 20.340 & 4.933 & NA & NA & NA & NA \\
II & 17 & 64.52 & 19.126 & 4.639 & 1.51 & 0.88468 & NA & NA \\
III & 11 & 70.22 & 11.851 & 3.573 & -7.18 & 0.49501 & 0.38645 & NA \\
IV & 9 & 43.62 & 28.168 & 9.389 & 33.41 & 0.03147 & 0.03398 & 0.01060 \\
\hline
\end{tabular}

Table S4. In vivo chick embryo CAM assay metastasis invasion analysis, including RQ, SEM, mean Cq, regression and p-value of relative amount of metastasis in the lower CAM for each group of eggs after treatment, compared to the control group (in which an arbitrary value of 1 was chosen). NA: not applicable.

\begin{tabular}{ccccccccc}
\hline \multirow{2}{*}{ Group } & Eggs & \multicolumn{4}{c}{ Metastasis Invasion Analysis } & \multicolumn{3}{c}{ P-value vs. } \\
\cline { 3 - 8 } & & RQ & SEM & $\begin{array}{c}\text { Mean } \\
\text { Cq }\end{array}$ & $\begin{array}{c}\text { Regression } \\
\text { (\%) }\end{array}$ & Group I & Group II & Group III \\
\hline I & 8 & 1 & 0.22931 & 25.79 & NA & NA & NA & NA \\
II & 8 & 0.71163 & 0.16585 & 26.28 & 28.84 & 0.8881 & NA & NA \\
III & 8 & 0.78216 & 0.12494 & 26.14 & 21.78 & 0.8881 & 0.8881 & NA \\
IV & 8 & 1.3026 & 0.41828 & 25.41 & -30.26 & 0.8881 & 0.5386 & 0.6067 \\
\hline
\end{tabular}


Setup of the in vivo chick embryo CAM assay

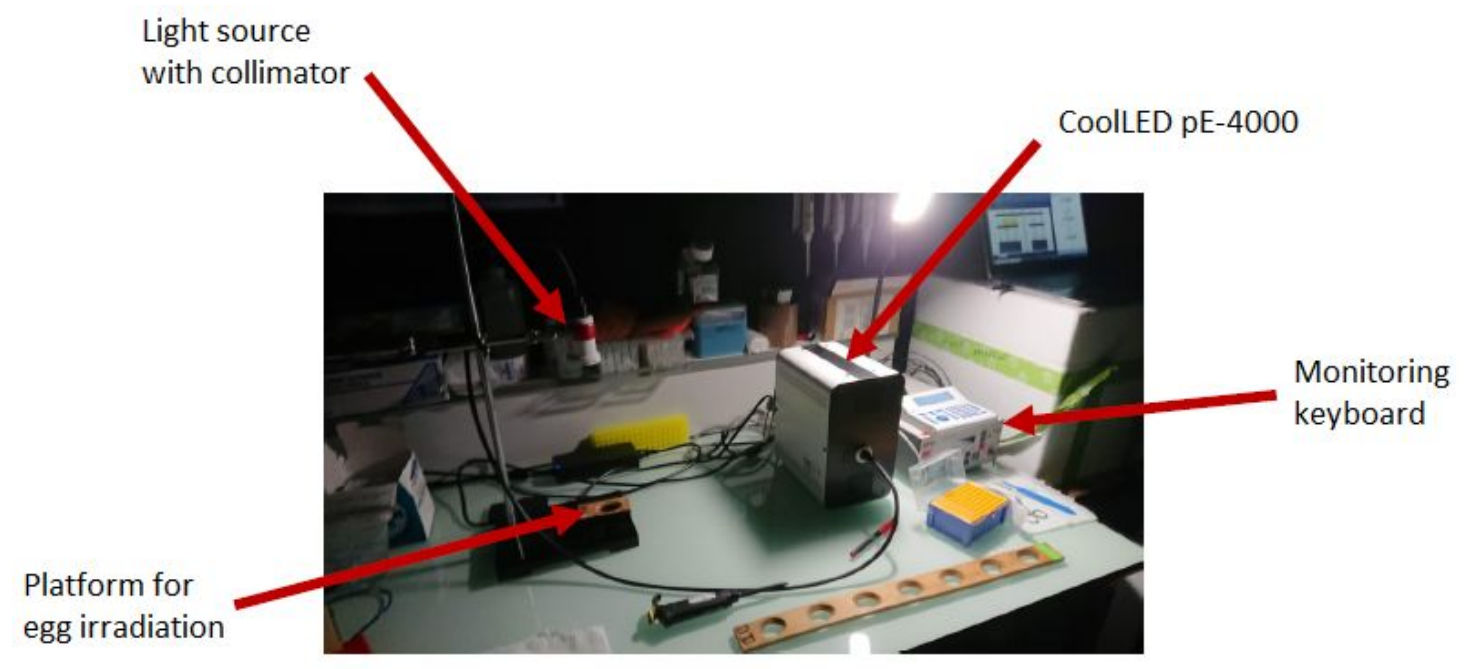

Figure S1. CoolLED pE-4000 universal illumination system used in the in vivo chick embryo CAM assay. 

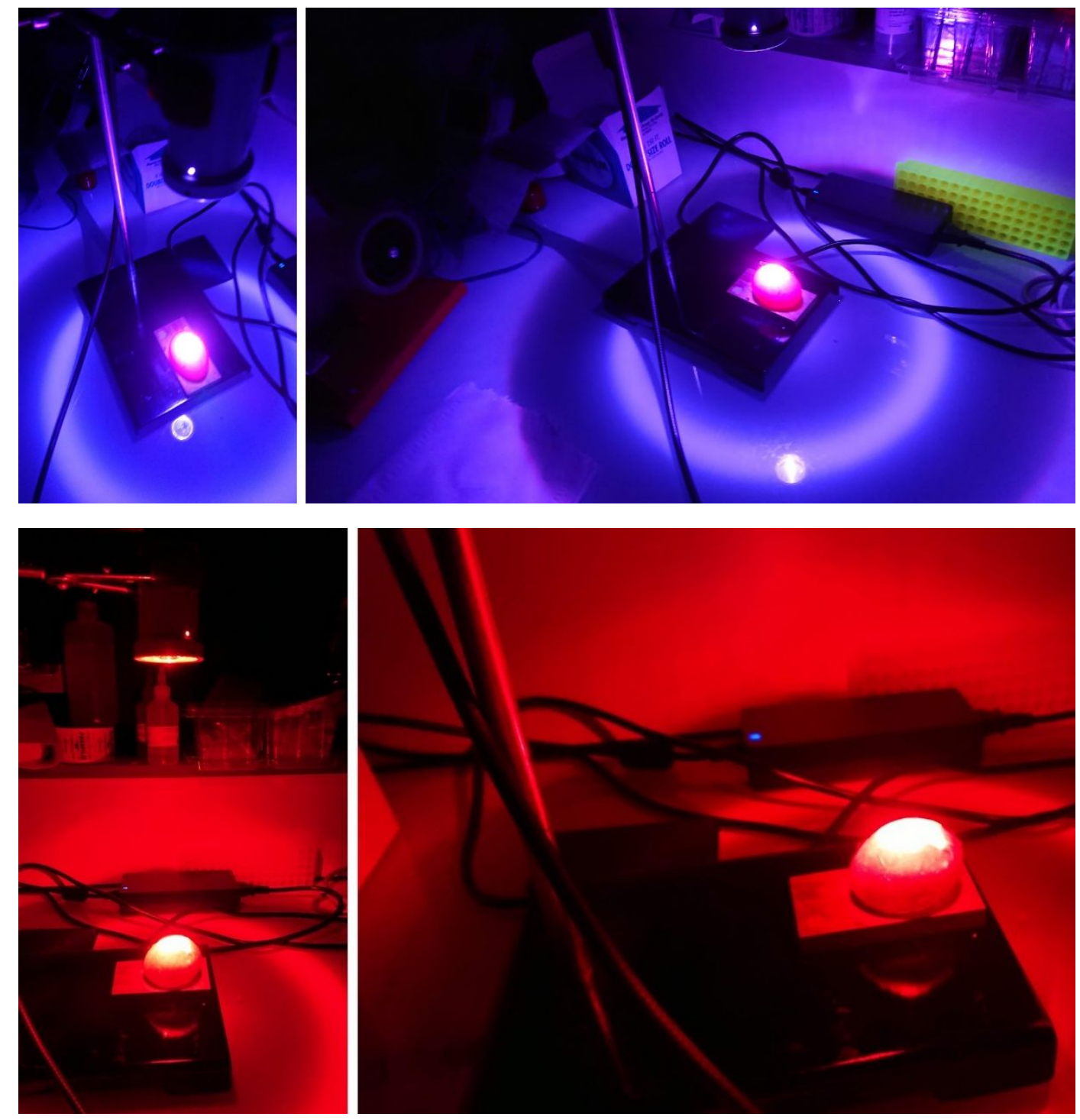

Figure S2. Top: calibration of the light source with collimator on eggs grafted with OE19 oesophageal adenocarcinoma cells at day eleven (E11) using white light, in order to achieve an effective illumination closely around the treated area, i.e centred in the tumor. Bottom: Irradiation of eggs grafted with OE19 oesophageal adenocarcinoma cells at day eleven (E11) using red light $(635 \mathrm{~nm})$ with a fluence of $2.5 \mathrm{~J} / \mathrm{cm}^{2}$. The distance between the surface of the upper CAM and the light source with collimator was $26 \mathrm{~cm}$ and the diameter of the circle illuminated in the upper CAM was $2.5 \mathrm{~cm}$. The time of irradiation needed to reach $2.5 \mathrm{~J} / \mathrm{cm}^{2}$ was $1 \mathrm{~min}$ at $83 \mathrm{~mW}$. 